\title{
Ley de Protección de Glaciares: el devenir de un conflicto socioambiental
}

\author{
Glaciers Protection Law: The evolution of a socio-environmental conflict
}

\section{Historial de la reseña}

Recibido:

25 de marzo 2019.

Aceptado:

23 de octubre de 2019

\author{
Javiera Herrera Pérez $z^{\mathrm{a}}$ y Alexis Segovia ${ }^{\mathrm{b}}$ \\ a Facultad de Ciencias Agronómicas, Universidad de Chile, Santiago, Chile. Correo electrónico: javierapazh@gmail.com. \\ b Facultad de Ciencias Forestales y de la Conservación de la Naturaleza, Universidad de Chile, Santiago, Chile.
}

\section{Palabras clave}

Conflicto socioambiental, glaciares, Ley de glaciares, Pascua Lama

\section{Keywords}

Glaciers, glacier law, Pascua Lama, Socio-environmental conflict

\section{Resumen}

El proyecto de ley de protección de glaciares ha suscitado gran interés político, empresarial, social y científico y se ha constituido como un conflicto socioambiental que va más allá de un territorio específico y que ha permitido en la expresión de los argumentos, a uno y otro lado, evidenciar diferentes miradas sobre el país, diferentes formas de percibir el desarrollo económico y que ha evolucionado desde un conflicto por elementos altamente tangibles (territorio, agua) hacia temas éticos y valóricos que cuestionan la institucionalidad del país y los paradigmas actuales de desarrollo.

Esta investigación plantea que el conflicto tiene su origen en el proyecto Pascua Lama y que ha evolucionado en la demanda de no repetir dicha experiencia, por lo que se indaga sobre la cronología del conflicto a través de la recopilación de notas de prensa y otras fuentes de información, analizando los hitos, sus actores y sus elementos, cosmovisiones y paradigmas, evidenciando que un conflicto puntual en un territorio determinado y vinculado a un proyecto específico, puede manifestarse como un problema de mucha mayor envergadura y alcance territorial a razón de una inadecuada gestión del conflicto puntual.

\section{Abstract}

The glaciers protection law project's has aroused great political, business, social and scientific interest and has constituted a socio-environmental conflict that goes beyond a specific territory and that has allowed in the expression to the arguments in a one and the other hand, to show different views about the country, different ways of perceiving economic development and that has evolved from a conflict with highly tangible elements (water, land) toward ethical and value issues that question the national institionality and current paradigms of development.

This investigation suggests that the conflict has its origin in the Pascua Lama project and that it has evolved in the demand not to repeat such experience, so that explore the chronology of the conflict through the collection of press releases and other sources of information, analyzing the milestones, its actors and its elements, worldviews and paradigms in conflict, evidencing that a specific conflict in a given territory and associated for a specific project, can manifest itself as a conflict of much far reaching and territorial scale at reason of inadequate management of the specific conflict. 


\section{Introducción}

Los conflictos socioambientales se pueden entender desde diferentes lógicas, como definiciones con una óptica antropocéntrica en torno a la naturaleza basadas en la relación utilitarista de los "recursos naturales", tal como lo define Reyes, Frontaura \& Leturia (2011): "Proceso caracterizado por una dinámica de oposición y controversia fundada en la incompatibilidad o percepción de incompatibilidad en torno al uso, acceso y/o preservación del ambiente y sus recursos" (p.62). Una forma diferente de entender los conflictos corresponde a la definición de Garrido, Vallejos \& Riquelme (2015), quienes definen un conflicto socioambiental como un "proceso donde se contraponen diferentes intereses, derechos, perspectivas, racionalidades o lógicas que se desarrollan de forma temporal en el espacio público, involucrando a más de un actor e implicando una acción colectiva" (p.59), definición que utilizaremos para la presente investigación y que se considera más amplia, ya que permite abordar diferencias entre los paradigmas y cosmovisiones, y deja espacio a las diferentes formas de aproximarse a la naturaleza por parte de diferentes culturas.

Respecto a la forma de investigar un conflicto socioambiental, Pollicardo \& France (2003) establecen la importancia de determinar la existencia de al menos dos grupos interdependientes, por lo que en los estudios y caracterizaciones de conflictos socioambientales habitualmente se realiza un análisis o mapa de los actores involucrados, para identificar estos grupos interdependientes. En estos análisis, es importante considerar que los objetivos y asimetrías de poder entre los diferentes actores, así como las cosmovisiones y paradigmas de los grupos sociales, suelen plasmar diferentes realidades y formas de relacionarse en el territorio.

Por otra parte, para que un conflicto social exista, la controversia u oposición debe ser ampliamente visible, lo que requiere de la comunicación a través de notas de prensa, imágenes, protestas y redes sociales, las que son determinantes del nivel de resonancia que un conflicto social pueda alcanzar (Astorga et al., 2017), por lo que para la presente investigación, la metodología se basó en una revisión cronológica de los hechos documentados en medios de prensa, que destacan aquellos hitos relevantes, considerados como aquellos puntos de inflexión en el curso de los acontecimientos que condicionan los hechos sucesivos.

Los conflictos socioambientales en Chile han sido sistematizados y reconocidos mediante el mapa de conflictos socioambientales, en el que la mayoría de estos se asocian al surgimiento de una iniciativa o proyecto puntual en un territorio determinado, lo que se evidencia con que noventa y dos de los 102 conflictos mapeados corresponden a conflictos asociados directamente a un proyecto de inversión. Sin embargo, el conflicto asociado al Proyecto de Ley de Protección y Conservación de Glaciares que no corresponde a un proyecto de inversión, igualmente constituye un conflicto socioambiental, tipificado por el mapa de conflictos del Instituto Nacional de Derechos Humanos (INDH) como el $\mathrm{N}^{\circ} 89$.

Respecto al origen del conflicto asociado a la iniciativa de creación de la ley de Protección y Conservación de Glaciares, existen diferentes opiniones. Mientras el INDH (2015) plantea que este se surge a partir de la iniciativa de Greenpeace denominada República Glaciar, que busca denunciar el vacío existente en la legislación chilena, en la que no se reconocerían los glaciares como parte del territorio, para otros autores, el conflicto se visibiliza a partir de una evolución del conflicto de Pascua Lama y posterior proyecto de expansión minero de la Corporación Nacional del Cobre (CODELCO), denominado "Andina 244 ". Incluso hay autores que atribuyen el origen de los conflictos entre glaciares y minería a los efectos del cambio climático y la escasez hídrica (Brenning \& Azócar, 2010; Kronenberg, 2013).

Otro elemento relevante de mencionar es que las afectaciones a glaciares, principalmente de tipo rocosos, asociadas a las intervenciones mineras son bastante más antiguas en el país que el proyecto Pascua Lama (Brenning \& Azócar, 2010), cabe señalar también que tanto glaciares rocosos como cubiertos son difíciles de detectar, además de presentar tasas de movimiento y variación de superficie mucho menos dinámica que los glaciares descubiertos (usualmente llamados "glaciares blancos"), lo que ha hecho que se intervengan sin cuidado alguno puesto que morfológicamente son similares al paisaje detrítico rocoso propio de las zonas con condiciones de permafrost. Dichas intervenciones e impactos sobre glaciares no evolucionaron en forma de conflictos, probablemente por desconocimiento público o por no atribuírsele importancia en aquel momento.

En este sentido, la iniciativa de Greenpeace de la "República Glaciar", más que marcar el comienzo de un conflicto, releva el problema a un nivel político y social.

Respecto a la situación de protección legal de los glaciares a nivel mundial se tienen dos tipos de protección: directa, a través de una legislación específica de protección, tal 
como es el caso de Argentina, primer país en tener una ley de protección de glaciares y en la Comunidad Autónoma de Aragón en España; y el segundo caso mediante una protección indirecta a través de su inclusión en áreas de protección oficial, como es el caso de Francia, Canadá, Estados Unidos y Colombia en que todos los glaciares se encuentran en parques nacionales (Herr, 2014).

Chile posee 24.114 glaciares en $23.641 \mathrm{~km} 2$ de superficie de hielo, lo que representa el $80,5 \%$ del total de hielo de Sudamérica (Segovia y Videla, 2017), por lo cual no se puede estar ajeno a la problemática de la susceptibilidad de los glaciares, y menos en el actual contexto de cambio climático y escasez hídrica, sobre todo porque en el territorio chileno además se ha detectado una evolución general de estas masas de hielo hacia un sostenido retroceso (Rivera, 1992; Rivera, Aravena \& Casassa, 1997; Rivera \& Casassa, 1999; Rivera, Casassa, Acuña \& Lange, 2000; Warren, Rivera \& Austin, 1997).

La presente investigación busca reconstruir cómo ha sido el proceso de desarrollo del conflicto asociado a la iniciativa del proyecto de ley de protección y conservación de glaciares en Chile y tiene como base hipotética que este se origina en un proyecto puntual, en este caso en el proyecto Pascua Lama, por lo que el principal objetivo es analizar como la evolución de un conflicto puntual en un territorio puede dar pie a un conflicto de mucho mayor alcance y cuyos elementos en disputa van mucho más allá de la competencia por determinados recursos, sino que permite apreciar diferencias en las cosmovisiones y paradigmas, que pone de manifiesto aspectos de corte ético y valórico, como el valor de legado y el valor de existencia, lo que revela diferencias en las formas de percibir la naturaleza desde una mirada antropocéntrica de corto plazo hacia una con atisbos biocéntricos.

\section{Materiales y métodos}

Esta investigación corresponde a la descripción analítica del conflicto asociado al proyecto de ley de protección y conservación de glaciares en Chile, a través de la recopilación de notas de prensa y otros antecedentes a fin de establecer una cronología del conflicto que permite analizar los siguientes aspectos:

- Origen y Evolución del conflicto

- Actores involucrados

- Elementos, paradigmas y cosmovisiones

\section{Recopilación de notas de prensa}

En concordancia con el planteamiento teórico, se realizó una búsqueda exhaustiva a través del buscador web de una plataforma digital de medios de prensa chileno (Emol) entre los años 2001 (origen del Proyecto Pascua Lama) y octubre de 2019 mediante la utilización de las palabras clave: glaciares y pascua lama, recopilándose todas las noticias en cuyo título apareciera una o más de dichas palabras, se consideraron como criterios de inclusión: 1) noticia sobre acontecimiento relacionado a proyecto de inversión vinculado a glaciares, y 2) noticia sobre Ley de Protección de Glaciares. A su vez, estas noticias podían estar relacionadas con: 1) aspectos técnicos del proyecto, 2) obtención de permisos ambientales, 3) implicancia sobre los glaciares, 4) oposición y manifestaciones, 4) opiniones desde el mundo político, 5) opiniones desde organismos técnicos, tales como el Servicio de Evaluación Ambiental (SEA), Superintendencia del Medio Ambiente (SMA), etc. y 6) opiniones desde las empresas o gremios. Aquellas noticias repetidas en más de un medio consultado se analizaron una sola vez, priorizándose la primera fecha de aparición.

Posteriormente, fueron clasificadas en las siguientes categorías:

1. Proyecto al que se refiere: Pascua Lama, Andina 244, Ley de Glaciares.

2. Tipo de actor(es) involucrado(s):

- Poder Ejecutivo (actores políticos): referido a comentarios sobre algún acontecimiento puntual emitido por autoridades políticas del Poder Ejecutivo de primer y segunda línea (presidente/a y/o ministros) o noticias sobre moción y/o propuesta de ley liderada desde el Poder Ejecutivo.

- Poder Ejecutivo (técnicos): referido a comentarios sobre algún acontecimiento puntual emitido por organismos técnicos del Gobierno/Estado (SMA, SEA)

- Poder Legislativo: referido a comentarios sobre algún acontecimiento puntual emitido por diputados y/o senadores, o noticias sobre moción y/o propuesta de ley, comisión investigadora u otra liderada desde el parlamento.

- Poder Judicial: referido a noticias vinculadas a instancias de judicialización de un conflicto (Tribunales ambientales, Cortes de Apelaciones o Corte Suprema), así como a comentarios sobre algún acontecimiento puntual emitido por algún miembro del Poder Judicial.

- Empresas y gremios: referido a comentarios 
Tabla 1

Resumen de fuentes periodísticas utilizadas.

\begin{tabular}{|c|cccc|cccc|}
\hline \multirow{2}{*}{$\begin{array}{c}\text { Medios } \\
\text { Consultados }\end{array}$} & \multicolumn{4}{|c|}{ Plataforma Emol } & \multicolumn{3}{c|}{ Otros } \\
\cline { 2 - 9 } & Emol & El Mercurio & Soy Chile & La Segunda & El Ciudadano & El Mostrador & La Tercera \\
\hline Total & 123 & 30 & 44 & 1 & 21 & 3 & 14 \\
\hline Ley de glaciares & 20 & 20 & 6 & 1 & 18 & 236 & 11 \\
\hline
\end{tabular}

Fuente: Elaboración propia.

sobre algún acontecimiento puntual emitido por las empresas titulares de algún proyecto vinculado a glaciares o a los gremios que agrupan a dichas empresas.

- Sociedad civil y Organizaciones no Gubernamentales (las ONG): referido a noticias vinculadas a acciones o a comentarios sobre algún acontecimiento puntual realizados u emitidos por la sociedad civil o las ONG relacionadas con alguno de los proyectos de inversión o proyecto de ley vinculados a la temática glaciar.

A esta revisión inicial, se añadieron algunas notas de prensa adicionales producto de una revisión no sistemática complementaria especialmente enfocada en ampliar los hitos y la recopilación de actores involucrados específicamente en el conflicto asociado al proyecto de ley de protección de glaciares, en que se incorporaron fuentes como $E l$ Mostrador, El Ciudadano, Diario Atacama y La Tercera, con lo que se completó la cronología.

La selección de la plataforma Emol (El Mercurio online) para la presente investigación obedece a que corresponde a una plataforma en la que se congregan todos los periódicos del grupo Edwards, con vasta tradición dentro del periodismo chileno y cuyo principal diario, El Mercurio, es considerado como el más influyente del país (García, 2009), además de poseer representación nacional a diferente escala a través de diarios regionales y nacionales

En la tabla 1, se presenta el resumen de las fuentes periodísticas revisadas clasificadas por fuente.

\section{Recopilación de antecedentes adicionales}

Una vez realizada dicha clasificación y orden, se pudo estructurar la cronología del conflicto, a la que fueron añadiéndose antecedentes recopilados a través de la revisión de tesis, columnas de opinión, presentaciones públicas y la revisión de la documentación del Poder Ejecutivo y Legislativo en torno al proyecto de ley de protección de glaciares (proyecto de ley, modificaciones, discusiones parlamentarias, declaraciones públicas, etc.)

\section{Resultados}

\section{Análisis de notas de prensa}

De la revisión sistemática, se analizó un total de 205 notas de prensa publicadas en las plataformas de Emol y que corresponden a dos criterios de búsqueda de información, de las cuales 145 fueron halladas con el criterio de búsqueda "Pascua Lama" y setenta con el criterio "glaciares".

Del total de notas analizadas, 149 se refieren al proyecto Pascua Lama, siete al proyecto Andina 244 y cuarenta y seis al proyecto de ley de protección de glaciares, lo que permite apreciar la magnitud de la importancia mediática del proyecto Pascua Lama, además de su gran extensión temporal y cantidad de hitos cronológicos.

Respecto a los actores involucrados, en la Figura $\mathrm{N}^{\mathrm{o}} 1$ se observa la distribución de la representación de los diferentes grupos de actores presentados en el análisis del total de notas de prensa (si se considera las dos palabras clave en la búsqueda), observándose importantes valores para la presencia en los medios del Poder Ejecutivo, y de las empresas y gremios, relegándose a menores valores, la presencia de la sociedad civil y las ONG, Poder Judicial y Poder Legislativo.

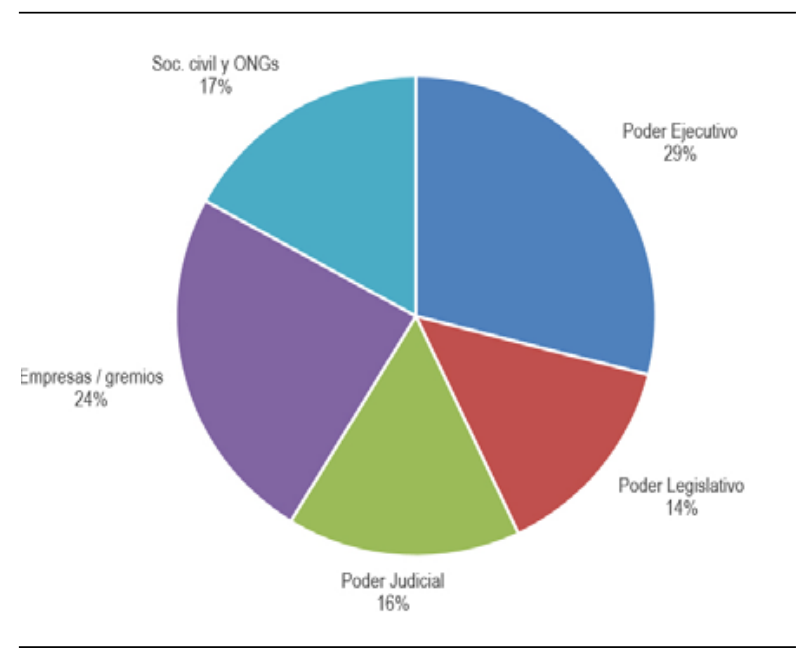

Figura 1. Análisis de actores presentes en las notas de prensa levantadas sistemáticamente. Fuente: Elaboración propia. 
Una vez que el registro de notas de prensa fue complementado con noticias, columnas de opinión y cartas al director en torno al tema específico del proyecto de ley de glaciares recopiladas en otros medios de comunicación, se tuvo un total de setenta y ocho notas de prensa referidas específicamente a dicho conflicto y al realizar el análisis de actores se logra identificar la relevancia del Poder Legislativo (28\%), de la sociedad civil y las ONG (25\%) y del Poder Ejecutivo (23\%) como actores más relevantes, lo que relega a las empresas y gremios con un $17 \%$, aparece el grupo científicos con un 6\% y el Poder Judicial disminuye a un $1 \%$, tal como se presenta en la Figura $\mathrm{N}^{\circ} 2$.

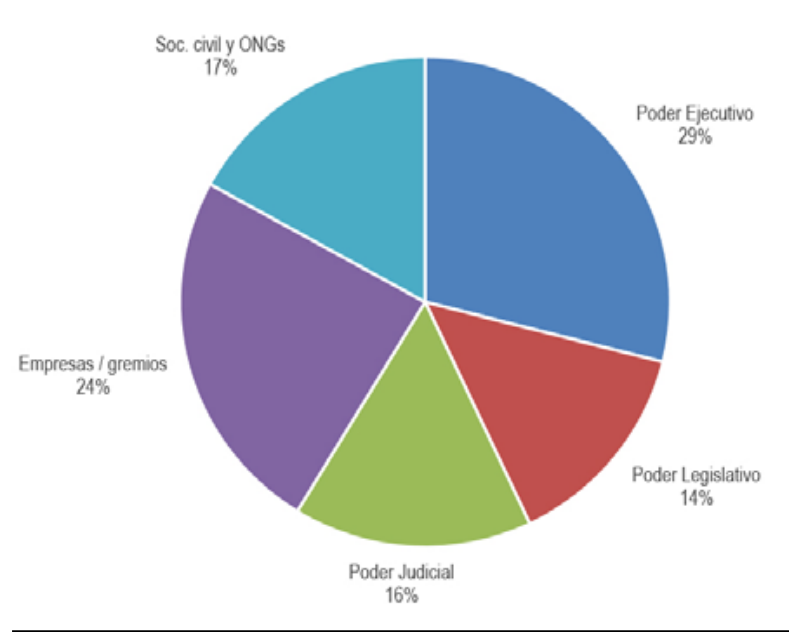

Figura 2. Análisis de actores involucrados en la discusión del proyecto de ley de glaciares. Fuente: Elaboración propia.

\section{Cronología del conflicto}

El año 2001 se da a conocer el proyecto Pascua Lama de Minera Barrick Gold, anunciándose que la compañía canadiense invertirá US\$35 MM en proyectos en Chile, Perú y Argentina.

Durante el proceso de Evaluación de Impacto Ambiental de dicho proyecto, se advierte la remoción de glaciares propuesta en el proyecto, $\mathrm{y}$ un conjunto de organizaciones ecologistas, académicas y asociaciones de agricultores iniciaron el año 2004 conversaciones para avanzar hacia una normativa de protección de los glaciares en Chile (Bórquez et al., 2006).

A nivel político, en el año 2005 el diputado Antonio Leal advierte que el proyecto destruirá tres glaciares: Toro I, Toro II y Esperanza, y de acuerdo a Segovia (2014) ese mismo año comienza la cronología en relación a la normativa de protección de glaciares con un proyecto de ley presentado por el mismo diputado Leal, conjuntamente con los diputados Leopoldo Sánchez, Roberto Delmastro y Arturo Longton, proyecto que establecía la prohibición de desarrollar proyectos de inversión en glaciares a través de un único artículo que consistía en una modificación al Artículo 11 de la ley 19.300 de Bases Generales del Medio Ambiente, en el cual se estipularía lo siguiente (Boletín N³947-12):

Con todo, ni aun sometiéndose al Sistema de Evaluación de Impacto Ambiental (SEIA) podrán desarrollarse actividades o ejecutarse proyectos en las zonas glaciares, salvo que estas tengan exclusivamente finalidades de investigación científica o de aprovechamiento ecoturístico o de aprovechamiento del derretimiento natural del hielo y el escurrimiento de las aguas. En estos casos, los proyectos deberán ser sometidos al SEIA (p.4).

Este proyecto de ley fue archivado en el año 2009, y en él se plantea la primera postura analizada (protección a todos los glaciares sin distinción) en la presente investigación. Durante el año 2005 la discusión se centró en el proyecto Pascua Lama, el cual fue ampliamente cuestionado por la propuesta inicial de remover casi 20 hectáreas de glaciares que se extraerían en bloques de hielo que serían transportados por camiones hacia la cumbre del glaciar Guanaco, de una superficie de 190 hectáreas, en el cual "estos se fusionarán unos con otros por recongelamiento y deformación en cuestión de horas de haber sido colocados, y continuarán deformándose y consolidándose por varios días" (El cuestionado proceso, 2005). Esta propuesta fue duramente criticada a través de argumentos técnicos que indicaban la inviabilidad de la propuesta, lo que desencadenó un conflicto social de gran envergadura, conflicto que aún se encuentra vigente en la región de Atacama y que ha estado caracterizado por una fuerte agitación social y política, lo que queda ampliamente consignado en el análisis de fuentes periodísticas.

En julio de 2005, en Copiapó, la entonces candidata a la presidencia Michelle Bachelet, en relación al proyecto Pascua Lama indicaba que "durante su Gobierno no se autorizaría ningún proyecto donde no se pruebe científicamente que no se generará un daño ambiental", declaración que puede dejar entrever la segunda postura analizada: evaluación caso a caso de los proyectos y su grado de afectación.

\footnotetext{
${ }^{1}$ Cuando un proyecto de ley pasa más de dos años en una comisión sin ser discutido es archivado.
} 
En febrero de 2006 (durante el gobierno de Ricardo Lagos y un mes antes que Bachelet asumiera como presidenta), la Comisión Regional del Medio Ambiente (COREMA) de la región de Atacama aprobó el proyecto Pascua Lama, tras imponer una serie de restricciones en la Resolución de Calificación Ambiental (RCA), entre las que se indican que la empresa no podrá intervenir los glaciares. De acuerdo al cronograma inicial, las obras de construcción comenzarían en mayo de 2006 y durarían por tres años para iniciar las operaciones en el año 2009.

Ese mismo año (2006), de acuerdo con la agenda comprometida por el gobierno electo de Michelle Bachelet, las organizaciones ecologistas formularon un proyecto de ley de protección de glaciares, a través de un grupo de trabajo compuesto por Chile Sustentable, la Sociedad Nacional de Agricultura, el Departamento de Medioambiente del Ejército, el Instituto Geográfico Militar (IGM) y la Fiscalía del Medio Ambiente (FIMA), hicieron entrega de la propuesta de proyecto de ley a la Secretaría General de la Presidencia (SEGPRES) el 30 de octubre de 2006 (Bórquez et al., 2006).

En el plano legislativo, en el año 2006, los senadores Antonio Horvath, Carlos Bianchi, Guido Girardi, Carlos Kuschel y Alejandro Navarro, mediante el Boletín $\mathrm{N}^{\circ} 4.205$ 12 , presentan un proyecto de ley sobre protección y conservación de glaciares, el que es discutido por largo tiempo, sin generar consenso (Segovia, 2014); mientras que en diciembre de 2008, los senadores Ávila, Girardi, Muñoz, Navarro y Ominami presentan una moción que establece normas de resguardo de los glaciares, la que fue archivada en 2014 (Boletín N6.308-12); y en 2009 los diputados Accorsi, Espinosa, Girardi, Lobos, Quintana, Rossi, Sepúlveda, Valenzuela y Venegas presentan una moción sobre reformas al Código de Aguas, Código de Minería y otros cuerpos legales, a fin de garantizar la conservación del medio ambiente y los recursos naturales (Boletín $\mathrm{N}^{\circ} 6.763-01$ ), moción que tampoco prosperó.

A nivel institucional, y tras la necesidad de generar información técnica respecto al tema de glaciares, el año 2008 se crea la Unidad de Glaciología y Nieves en la Dirección General de Aguas, y se comienza a hacer el inventario nacional de glaciares (Segovia, 2014).
El año 2009 se genera la Política para la Protección y Conservación de Glaciares, y la Estrategia Nacional de Glaciares a cargo de la Dirección General de Aguas (Segovia, 2014).

El año 2010 se reforma la Institucionalidad ambiental del país a través de la ley 20.417 , que, respecto a la protección de glaciares, esta modificación incluye la palabra "glaciares" en el artículo 11, letra d de la ley 19.300, lo cual indica que los proyectos o actividades susceptibles de causar impacto ambiental en localizaciones próximas a glaciares requerirán la elaboración de un Estudio de Impacto Ambiental. También incluye la palabra "glaciares" en el artículo 36 de la ley 19.300; esto indica que los glaciares ubicados dentro del perímetro de las áreas protegidas formarán parte de estas mismas (ley 20.417), medida que va en la línea de la moción de analizar caso a caso los proyectos y el grado de afectación de los glaciares.

Mientras tanto, la ejecución de las obras del proyecto Pascua Lama siguieron generando focos de conflicto en el valle del Huasco, entre los que se cuentan tomas de caminos, protestas en diferentes regiones y acusaciones de mermas en los caudales del río Huasco, y en el año 2013, el proyecto sufre severos traspiés luego que el Servicio de Evaluación Ambiental (SEA) de Atacama detectara incumplimientos en los compromisos estipulados en la Resolución de Calificación Ambiental (RCA), por lo que la empresa es multada (USD 255.026 en marzo y USD 81.422 en $\mathrm{abril}^{2}$ ), posteriormente la Corte de Apelaciones de Copiapó suspende las faenas después de acoger la orden de no innovar presentada por comunidades diaguitas de la zona, en mayo se crea una comisión investigadora en la Cámara de diputados y a fines de ese mismo mes, la Superintendencia de Medio Ambiente aplica una sanción correspondiente a una multa de USD 16,7 millones $^{3}$ y la paralización de faenas, lográndose determinar veintitrés incumplimientos ambientales de la RCA. Los motivos principales de las infracciones son el inadecuado manejo de aguas e incumplimientos en el plan de monitoreo de los glaciares. La Corte de Apelaciones de Copiapó ratifica la paralización y la empresa reconoce las infracciones.

Ese mismo año, en el marco de la campaña presidencial, aparecen entre algunos candidatos presidenciales las críticas al proyecto Pascua Lama y la propuesta de generar una ley de protección de glaciares. Por su parte,

\footnotetext{
${ }^{2}$ Para el cálculo en USD se consideran valores de UTM y dólar observado a 30 de marzo y 31 de abril de 2013 según el Servicio de Impuestos Internos de Chile (SII).

${ }^{3}$ Para el cálculo en USD se considera el valor observado al 31 de mayo según el SII.
} 
Michelle Bachelet (candidata que posteriormente asume la presidencia), durante la segunda campaña incorporó en su programa de gobierno un párrafo alusivo a glaciares con la finalidad de declararlos como bienes nacionales de uso público, mientras que el ministro de Minería, Hernán De Solminihac, señalaba que el proyecto tenía que salir adelante por su importancia para el país.

En marzo de 2014, durante el segundo gobierno de Michelle Bachelet, Greenpeace lanza la campaña de creación de una República Glaciar, lo que, de acuerdo a Matías Asún, director de Greenpeace-Chile, es posible debido a que "en la Constitución no existe mención a los glaciares como bien público que debe protegerse activamente". Esta campaña buscó sensibilizar a la población sobre la importancia de contar con una normativa que proteja los glaciares y a su vez presionar al gobierno para que se pronuncie frente a este tema (Segovia, 2014), campaña que solicitó el pronunciamiento de la presidenta Bachelet en su discurso del 21 de mayo, frente a su disposición a impulsar una ley de protección de glaciares para Chile.

El 20 de mayo de 2014, la denominada Bancada Glaciar, conformada por los diputados Camila Vallejo, Cristina Girardi, Andrea Molina, Giorgio Jackson, Vlado Mirosevic, Luis Lemus, Patricio Vallespín, Daniel Melo y Leonardo Soto ingresan un proyecto de ley que busca proteger los glaciares (Boletín $\mathrm{N}^{\circ}$ 9.364-12) e hicieron un llamado a la presidenta de la República a patrocinar el proyecto y mencionar el tema en el discurso del día siguiente.

El 21 de mayo de 2014, la presidenta Bachelet anuncia en su cuenta pública la creación de un proyecto de ley que dará protección a los glaciares y en septiembre de ese año, tras participar en la cumbre del cambio climático en la Organización de las Naciones Unidas (ONU), el ministro de Medio Ambiente, Pablo Badenier, reafirma la intención de legislar durante este año, lo que se materializa en marzo de 2015 cuando se presenta la indicación sustitutiva respecto al proyecto de ley ingresado desde la Cámara de diputados el año 2014, asilo que da inicio a una tramitación por parte del Poder Ejecutivo del proyecto de ley de protección de glaciares.

A partir de esa fecha, año 2015, comienza la discusión en torno a la forma de protección necesaria, presentándose la negativa de varios de los diputados que presentaron la propuesta de ley en 2014 a aprobar la ley postulada por el Ejecutivo, primero por considerarla insuficiente, y con posterioridad considerándola definitivamente un retroceso en la protección de los glaciares.

El año 2015, en su informe anual, el INDH señala que respecto a la indicación sustitutiva ingresada por el Poder Ejecutivo, la protección de los glaciares disminuye considerablemente y concluye para establecer que "la posición del Poder Ejecutivo en orden a disminuir la protección inicial, es de preocupación, ya que no se establece una protección general a los glaciares, y además desprotege otras categorías de hielos, como el permafrost, que sí cumpliría funciones análogas a los glaciares" (INDH, 2015).

Por otra parte, el año 2016, la Corte Suprema de Justicia envió a la Comisión de Medio Ambiente de la Cámara de diputados un informe donde analizaba la propuesta de ley que advertía incoherencias y medidas regresivas en torno a la protección de glaciares.

El 20 de junio de 2018, y luego de cuatro años, la ministra de Medio Ambiente del gobierno de Sebastián Piñera, anuncia públicamente el retiro de la Ley de Protección de Glaciares, pues indica que algunos de los elementos contemplados en la ley serían incorporados al Código de Aguas y a la ley que crea el Servicio de Biodiversidad y Áreas Protegidas (SBAP).

El 4 de julio de 2018, el senador Guido Girardi, junto a los senadores Manuel José Osandón, Rafael Prohens, y las senadoras Isabel Allende y Ximena Órdenes presentan un proyecto sobre protección de glaciares (Boletín $\mathrm{N}^{\circ} 11.876$ 12), el cual se basa en propuestas presentadas anteriormente y la ley de Argentina como referencia. El 12 de marzo de 2019, la Comisión de Medio Ambiente y Bienes Nacionales del Senado aprobó por unanimidad la idea de legislar el proyecto de ley de protección de glaciares.

Dentro de los puntos más destacados de este proyecto de seis artículos, más un artículo transitorio, se tiene que su objeto es la protección de los glaciares, el periglacial y permafros $t^{4}$ por considerar estos ambientes esencialmente como reservas estratégicas de recursos hídricos. A su vez, plantea que la naturaleza jurídica de los glaciares será de bienes nacionales de uso público protegidos, con fines de conservación e inapropiables. Como restricciones, quedan prohibidas las actividades

\footnotetext{
${ }^{4} \mathrm{El}$ permafrost se define como tierra (tierra o roca e hielo o material orgánico incluido) que permanece a $0{ }^{\circ} \mathrm{C}$ o menos durante al menos dos años consecutivos. Ver https:/ipa.arcticportal.org/publications/occasional-publications/what-is-permafrost
} 
que puedan afectar su condición natural, las que impliquen su destrucción o traslado o interfieran en su avance como liberación, dispersión o disposición de sustancias o elementos contaminantes, construcción de obras de infraestructura con excepción de aquellas necesarias para la investigación científica y la prevención de riesgos, la exploración y explotación minera e hidrocarburífera, la instalación de industrias o desarrollo de obras o actividades industriales. En cuanto a las sanciones y multas, plantea que las acciones o actividades en contravención con la ley serán sancionadas con presidio menor en su grado mínimo a máximo y con multa de USD 6.777 a $67.776^{5}$. Además, su artículo transitorio estipula que: "Las actividades, de cualquier naturaleza, que al momento de la vigencia de la presente ley afecten o puedan afectar glaciares deberán cesar y requerir de las autoridades competentes las autorizaciones que procedan conforme a la ley". Cabe señalar que este proyecto generó de inmediato oposición de los sectores productivos, especialmente el rubro minero, por considerarlo demasiado restrictivo, además de señalar lo complicado que será establecer restricciones en zonas de permafrost y ambiente periglaciar, puesto que ello implicaría una restricción en gran parte del país, inclusive en zonas que están alejadas de glaciares pero que aún conservan condiciones de permafrost o ambiente periglaciar. Por otro lado, los sectores productivos se opusieron tenazmente al artículo transitorio que obligaría a detener las actividades si es que ya estaban afectando glaciares, vale decir, una oposición a la retroactividad de la ley.

Luego, el 13 de septiembre de 2019, el Ejecutivo ingresó un documento $\left(\mathrm{N}^{\circ}\right.$ 184-367) que formula una indicación sustitutiva al proyecto de ley sobre "protección de glaciares" y que busca sustituir el texto íntegro del proyecto anterior. En este nuevo articulado, el objeto es la protección de los glaciares del territorio nacional para conservar sus servicios ecosistémicos en cuanto a reservas de recursos hídricos. Por esto, el nuevo articulado elimina la protección del permafrost $\mathrm{y}$ el ambiente periglacial, y lo cambia por el concepto de "Entorno glaciar" como un “Área próxima a glaciares que posibilita la mantención de los servicios ecosistémicos en cuanto a reservas de recursos hídricos y en que los impactos que en dicha área se produzcan puedan afectar en forma indirecta pero significativa a los glaciares". En cuanto a las restricciones, esta indicación plantea prohibir la realización de todo proyecto o actividad que pueda afectar a glaciares que se ubiquen en reservas de región virgen y parques nacionales, y que se excepcionan de la prohibición las obras necesarias para la investigación científica y la gestión de riesgos asociados a glaciares, así como las obras de infraestructura pública y acciones fundadas en el interés nacional. Se prohíbe la remoción, traslado y cubrimiento con material de desmontes y/o escombros que pueda afectar a los glaciares. Para la ejecución de cualquier otra alteración a glaciares se deberá contar con un Permiso Ambiental Sectorial (PAS) específico otorgado por la Dirección General de Aguas a través del Sistema de Evaluación de Impacto Ambiental y los proyectos, obras o actividades que cuenten con algún tipo de permiso para realizar actividades en glaciares o su entorno, otorgados con anterioridad a la entrada en vigencia de la presente ley, no quedarán afectos a sus disposiciones.

Este último articulado comete nuevamente el error de la indicación sustitutiva del año 2015, también presentada por el Ejecutivo, aunque en dicha situación con Michelle Bachelet como presidenta de la República, en que se pretende proteger solo los glaciares ubicados en reservas de región virgen y parques nacionales, ya que esto en sí no representa un avance en protección de glaciares, puesto que en Chile no existe ni siquiera una reserva de región virgen, por lo que no hay glaciares dentro de aquella categoría de área silvestre protegida (ASP), y en el caso de los parques nacionales, estos ya cuentan con la protección de esta figura de ASP y no existe ningún glaciar bajo esta categoría entre las regiones de Atacama y el Maule. Además, solo reconoce la importancia de los servicios ecosistémicos de los glaciares desde el punto de vista de los recursos hídricos (servicios de provisión), sin considerar su importancia como reguladores climáticos, mantención de la biodiversidad local y la importancia cultural de los mismos. Por último, deja la puerta abierta a la intervención de glaciares mediante el otorgamiento de un Permiso Ambiental Sectorial específico, además de eliminar la retroactividad en materia ambiental que sí propone el proyecto de ley presentado por el senador Guido Girardi.

Este proceso es aún, a noviembre de 2019, un tema en desarrollo y de discusión en el Congreso nacional.

Por su parte, el proyecto Pascua Lama se encuentra cerrado temporalmente. En 2018 además la SMA sancionó el cierre definitivo, que posteriormente fue

${ }^{5}$ Para el cálculo en USD se consideran valores de UTM y dólar observado a 30 de octubre de 2019 según el Servicio de Impuestos Internos de Chile (SII). 

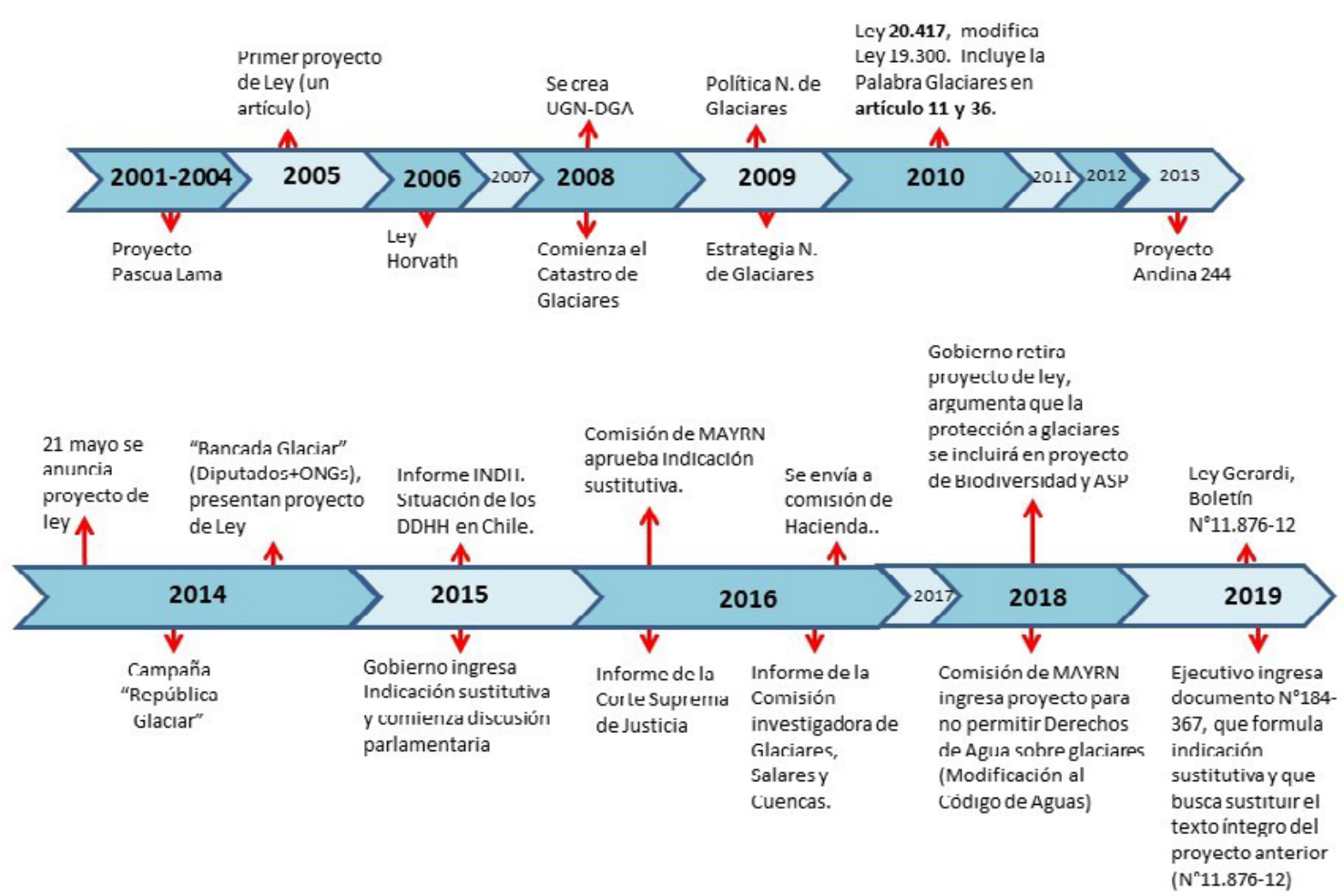

Figura 3. Hitos políticos en materia de glaciares. Fuente: Elaboración propia.

rechazada por el Tribunal Ambiental y cuyo titular ha mencionado que se encuentran desarrollando un nuevo proyecto de minería subterránea.

La Figura $\mathrm{N}^{\circ} 3$ presenta los hitos políticos en materia de glaciares en Chile, donde se refleja gran parte de la cronología de este conflicto.

\section{Origen y evolución del conflicto}

Muchos de los conflictos ambientales y socioambientales tienen su origen en proyectos de inversión puntuales situados en territorios determinados y cuyas externalidades sociales y ambientales tienen implicancias sobre dicho territorio, sus recursos y la población que en ellos habita, y bajo este entendido es que se han desarrollado diferentes técnicas de resolución de los conflictos, que buscan enfrentarlos como elementos singulares en un territorio y con actores definidos. El conflicto en torno a la ley de protección de glaciares no presenta dicha lógica en términos exactos, ya que el territorio abarcado y los actores involucrados no son fácilmente identificables ni convocables para trabajar en torno a una metodología de resolución de conflictos, por ser un conflicto territorial de interés nacional en relación a una medida normativa y que ha evolucionado para dejar de manifiesto cuestionamientos a la institucionalidad y paradigmas de desarrollo en que se sustenta el país.

Sin embargo, tal como se indicó previamente, el origen del conflicto analizado es atribuible principalmente a la evolución en torno al Proyecto Pascua Lama y complementado por el proyecto de expansión denominado Andina 244, ambos situados en territorios con presencia glaciar y en cuyos estudios de impacto ambiental y procesos de participación ciudadana los principales cuestionamientos técnicos y ciudadanos estuvieron dados por la afectación de glaciares, los impactos que esto tendría en el ciclo hidrológico de la cuenca y la consecuente disminución de recursos hídricos para otras actividades como la agricultura.

\section{Actores involucrados}

En relación al conflicto originado por el proyecto Pascua Lama, de acuerdo al análisis de conflictividad realizado por Hernández y Sazo (2015), este corresponde al conflicto de mayor intensidad en Chile entre los años 2000 y 2013, el que clasificándose entre aquellos de 


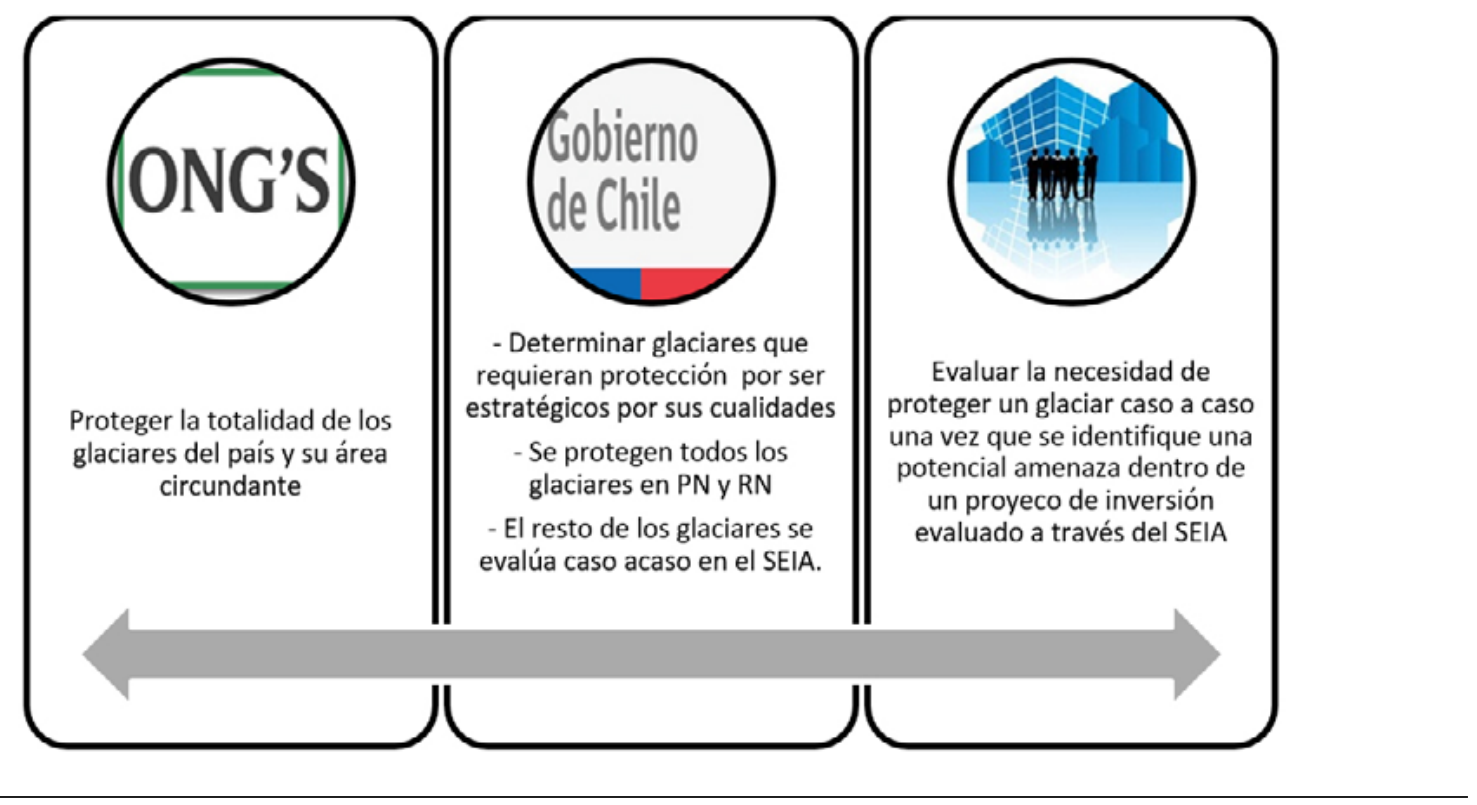

Figura 4. Representación esquemática de tres de las posturas manifestadas frente a la forma en que debería operar la Ley de Protección de Glaciares. Fuente: Elaboración propia.

conflictividad extrema se caracteriza por la identificación de al menos tres sectores opositores al proyecto: sectores locales, ambientalistas y políticos, donde los primeros son los encargados del activismo y la oposición, los segundos entregan asesoría y capacitación legal a las comunidades, mientras que el sector político actúa como canal de comunicación con las autoridades. En virtud del análisis realizado a las notas de prensa complementado con noticias, columnas de opinión y cartas al director en torno al proyecto de "Ley de Glaciares", se logra vislumbrar un mapa de actores en que se distinguen dichos grupos además de muchos otros con diferentes roles y posiciones:

- Comunidad local en torno a proyectos de inversión que amenazan la existencia de glaciares

- Las ONG

- Poder Legislativo

- Empresas y gremios mineros

- Actores políticos del Gobierno

- Comunidad científica

\section{Elementos, paradigmas y cosmovisiones en conflicto}

Centrándose en la discusión del proyecto de ley propuesto el año 2014 en la Cámara de diputados (bancada glaciar) y la moción presentada por el Ejecutivo a dicho proyecto en el año 2015, se observa que en la discusión se representan claramente tres posturas en torno a este conflicto:

1. Protección a todos los glaciares sin distinción.

2. Identificación de algunos glaciares relevantes que deban ser protegidos.

3. Determinación caso a caso de los potenciales impactos y la importancia de proteger a cada glaciar.

Entre los argumentos explícitos identificados en la recopilación de proyectos de ley, declaraciones de prensa, documentos de trabajo, publicaciones, etc., pueden clasificarse de forma muy sintética y solo con el fin de graficar la gradiente de posturas en tres tipos de posición manifestado a través de la forma en que esta ley debiera operar, las que se representan en la Figura $\mathrm{N}^{\circ} 4$. En ella se observa, por una parte, la posición del ala más proconservación de los glaciares, compartida principalmente por las $\mathrm{ONG}$, agrupaciones ciudadanas y un sector del Parlamento, en la que se propone proteger todos los glaciares del país y el medio en el que se sustentan; por otra parte, se encuentra la postura que prima entre las empresas y gremio minero, cuya postura es la de evaluar caso a caso de acuerdo a lo estipulado en el SEIA. Asimismo, la propuesta del gobierno se manifiesta como una propuesta intermedia, en la que se propone identificar algunos glaciares específicos como objeto de protección, proteger además la totalidad de los glaciares presentes 
en parques nacionales, reservas nacionales y reservas de regiones vírgenes ${ }^{6}$ y el resto sería evaluado caso a caso. Las visiones contrapuestas y la polarización existente principalmente entre las dos posturas extremas dejan de manifiesto la percepción de incompatibilidad en las metas, que es otro de los elementos básicos de un conflicto (Pollicardo \& France, 2003).

Respecto a los argumentos implícitos que sustentan la contraposición de las posturas, se puede observar que una de las posturas releva la necesidad de generar una legislación que dé protección efectiva a todos los glaciares y parte de la premisa de un principio precautorio en que es necesario conservar la totalidad de los glaciares, debido a que todos constituirían una reserva estratégica hídrica, postura que es compartida por diversas ONG y que es avalada por el Instituto de Derechos Humanos, que argumenta que el devenir de los glaciares impacta en el goce y ejercicio de diversos derechos humanos (INDH, 2015).

Por otra parte, la posición del gremio minero difundida por el Consejo Minero ${ }^{7}$ se basa en que la sustentabilidad requiere un equilibrio entre la adecuada protección de los glaciares y el necesario desarrollo económico del país y establece que no todos los glaciares tienen la misma significancia hídrica, por lo que debieran ser evaluados caso a caso, para lo cual el SEIA debiese ser el instrumento que permita dicho análisis.

Finalmente, el proyecto de ley presentado en 2015 por el Gobierno presenta una postura intermedia que diferencia entre tres tipos de glaciares:

- Glaciares con carácter de reserva estratégica.

- Glaciares situados en parques nacionales, reservas naturales y reservas de regiones vírgenes.

- Los demás glaciares.

De estos, solo tendrían algún grado de protección los dos primeros, es decir aquellos que se encuentren en una reserva, en un parque nacional o aquellos glaciares que sean una reserva hídrica relevante y que sean declarados como reserva estratégica por los ministros de Obras Públicas y Medio Ambiente, previo informe de la Dirección General de Aguas (INDH, 2015).
Las posturas presentadas plantean puntos de vista contrapuestos y denotan intereses divergentes no solo a una legislación particular, sino que plantean diferencias en la forma de conceptualizar el desarrollo del país.

La propuesta de evaluar caso a caso los impactos en virtud de un Estudio de Impacto Ambiental corresponde a la postura menos proconservación de glaciares, ya que permitiría el planteamiento de proyectos de inversión en cualquier territorio, sin restringir por la existencia de zonas glaciarizadas, y evaluaría en virtud de lo declarado y comprometido por el titular del proyecto, lo que de acuerdo a la experiencia con el proyecto Pascua Lama no se condice con una medida de protección adecuada, porque aunque la empresa sea multada y se paralicen las faenas, los potenciales daños podrían ser irreparables. Por otra parte, el gasto fiscal asociado a la evaluación por parte del Estado, la fiscalización, procesos sancionatorios y enfrentamiento en tribunales es elevado.

La propuesta del gobierno se analizará en virtud de la clasificación de nivel de protección indicada anteriormente:

Glaciares en áreas protegidas: permite la protección de glaciares en parques nacionales y reservas nacionales, con la observación que no hay ningún glaciar dentro de parques nacionales entre las regiones de Atacama y El Maule, regiones donde se concentra la mayor cantidad de actividad minera, coincide con las franjas de ubicación de glaciares y presenta las mayores demandas hídricas por concepto de actividad agrícola. Respecto a las reservas nacionales, aquellas que poseen mayor número y superficie de glaciares son las que se ubican en las regiones de Aysén y Magallanes, donde existe entre las regiones de Atacama y el Maule solo una unidad con una superficie de 30,6 km² (Segovia, 2015). Además, al considerar que en Chile existen leyes como el Código de Aguas y el Código Minero, estas potencialmente podrían vulnerar dicha protección (Herr, 2014).

Respecto a la declaración de reserva estratégica, de acuerdo a Herr', esta propuesta tendría los siguientes inconvenientes.

\footnotetext{
${ }^{6}$ En el país no existe actualmente ningún área protegida en esta categoría.

${ }^{7}$ Opiniones difundidas en medios de prensa a través de entrevistas y cartas de opinión a nombre del presidente del Consejo Minero.

${ }^{8}$ Presentación realizada por Leslye Herr en Taller de ecosistemas glaciares, Magíster en Áreas Silvestres y Conservación de la Naturaleza, Universidad de Chile.

${ }^{9}$ Presentación realizada en Taller de ecosistemas glaciares, Magíster en Áreas Silvestres y Conservación de la Naturaleza, Universidad de Chile.
} 
- El glaciar no adquiere carácter de tal hasta que medie una declaración oficial.

- El Estado debe conducir un procedimiento científico y administrativo para declarar cuáles glaciares deben ser protegidos.

- Alto costo.

- Algunos glaciares serían protegidos en desmedro de los demás.

- Carga de la prueba recae en el Estado.

Al seguir con esta línea argumentativa, la Corte Suprema, en su oficio $\mathrm{N}^{\circ} 110-2016$ de fecha 8 de agosto de 2016, plantea que los glaciares son bienes nacionales, que forman parte del patrimonio ambiental de Chile y no pueden ser objeto de proyectos de inversión con fines económicos. No obstante lo anterior, advierte que el contenido del proyecto de ley sobre protección de glaciares podría debilitar la situación de los glaciares, al regular un procedimiento que posibilitará su explotación, puesto que el artículo $1^{\circ}$ establece que los glaciares constituyen "reserva de agua dulce" 10 , lo que implica que se podría disponer de ellos en el futuro próximo o lejano. Asimismo, el artículo $4^{\circ}$ establece su naturaleza jurídica sindicándolos como bienes nacionales de uso público ${ }^{11}$, en circunstancias que forman parte del patrimonio ambiental de Chile, de modo que su categoría corresponde a la de bienes nacionales, conforme el inciso $1^{\circ}$ del artículo 589 del Código Civil, dado que su uso no lo puede disponer la autoridad. Así, entonces, los glaciares no son un bien explotable, bajo ningún respecto.

En definitiva, la Corte Suprema concluye que; "queda claro que la iniciativa permite desarrollar proyectos, obras y actividades de distinto orden, entre ellas las económicas: a) en los glaciares no incluidos en la declaración de reserva estratégica; b) en el entorno de los glaciares afectos a la declaración de reserva estratégica; y c) en los glaciares incluidos en la declaración de reserva estratégica, pero desafectados. En este aspecto, la iniciativa de proyecto de ley podría ser regresiva y eventualmente transgredir el principio de no regresión en materia medioambiental, que se encuentra recogido en diferentes instrumentos internacionales y jurisprudencia nacional e internacional".
Asimismo, el informe de la "comisión especial investigadora de los actos de los organismos públicos competentes, encargados de la fiscalización y protección de glaciares, cuencas hidrográficas y salares de chile" de la Cámara de diputados, de fecha 22 de diciembre de 2016, plantea dentro de sus conclusiones que:

- Si bien Chile tiene el $82 \%$ de los glaciares ubicados en Sudamérica, aún no ha sido posible generar un cuerpo normativo con una protección adecuada a la importancia que debiese darse a los glaciares, y aun cuando el desarrollo económico del país es fundamental, el Estado no puede privilegiar los intereses privados por sobre y en desmedro del cuidado de nuestros recursos naturales.

- Detecta problemas relacionados con la baja inclusión de la ciudadanía en los procesos de toma de decisiones y que las organizaciones civiles que defienden los ecosistemas están en desventaja, ya que no cuentan con la asesoría legal y técnica que les permita defenderse en igualdad de condiciones, frente a megaempresas que sí cuentan con recursos suficientes.

- Por último, solicita al Ejecutivo poner urgencia al proyecto que reforma el Código de Aguas en materia de la priorización de sus usos como, asimismo, mayor disponibilidad en la tramitación del proyecto sobre protección y preservación de los Glaciares (Boletín $\mathrm{N}^{\circ}$ 9364-12), el cual debe ser mejorado en varios aspectos para cumplir con el objetivo propuesto de resguardar efectivamente a los glaciares.

De acuerdo a algunos científicos y las ONG, el objeto de protección debe contener los ambientes glaciares, periglaciares y permafrost, lo cual regula o bien prohíbe las actividades que puedan realizarse en o en torno a ellos, lo que se refleja claramente en el espíritu de la propuesta de ley presentada en 2014, cuyo argumento es que los glaciares son ecosistemas complejos asociados a los ambientes glaciares y periglaciares, que forman parte del ciclo hidrológico (Boletín 9364-12). Es importante señalar también que, en la definición de los conceptos de glaciar, ambiente glaciar, ambiente periglaciar y permafrost tuvo participación el Instituto Geográfico Militar, que recopila antecedentes bibliográficos y proponiendo definiciones propias (IGM, 2014).

\footnotetext{
${ }^{10}$ Artículo $1^{\circ}$. Objeto. La presente ley tiene por objeto la protección, conservación y preservación de los glaciares y su entorno definido en esta ley, ubicados en el territorio nacional, los que se reconocen como parte del patrimonio ambiental del país, constituyen reservas de agua dulce, cumplen funciones ecosistémicas y proveen servicios ecosistémicos.

${ }^{11}$ Artículo $4^{\circ}$. Naturaleza jurídica. Los glaciares son bienes nacionales de uso público. Como tales no son susceptibles de apropiación. Además, en ellos no podrá, bajo pretexto alguno, constituirse derechos de aprovechamiento de aguas.
} 
Otro elemento relevante para los científicos corresponde a la consideración de riesgos asociados a la dinámica de la criósfera y a su inestabilidad debido a procesos de cambio climático. En este sentido, como plantea Iribarren et al. (2018), pasar por alto la dinámica de los glaciares, podría retrasar las acciones necesarias para mitigar los peligros de los glaciares, lo que pone poblaciones en riesgo, lo que sin duda podría generar nuevos conflictos socioambientales. Por ejemplo, en los Andes centrales argentinos y chilenos, el riesgo asociado a los glaciares ha sido mayormente por el avance glaciar episódico e impactos hidrológicos de bloqueo de arroyos de montaña, y colapso de lagos con represas de hielo (Iribarren at al., 2015). Por su parte, en la Patagonia, los glaciares responden rápidamente al clima, por lo general retrocediendo y adelgazándose considerablemente en las últimas décadas (Davies y Glasser, 2012; Paul y Mölg, 2014). Este retiro glacial ha dado lugar a la formación y crecimiento de un gran número de lagos glaciares (Loriaux y Casassa, 2013).

Por otra parte, la indicación sustitutiva presentada por el Ejecutivo a dicho proyecto solo considera a los diferentes tipos de glaciares y a su entorno, definiéndolo como la zona de captura nival que alimenta al glaciar, así como el área comprendida entre el frente terminal actual del glaciar y quinientos metros aguas abajo, medidos sobre la topografía del terreno (Oficio 1170-362, 2015), lo que posteriormente se amplió a mil metros luego de discutido y aprobado el articulado de la indicación sustitutiva.

Otro elemento detectado en la discusión en torno al proyecto de ley de protección de glaciares corresponde a la forma de percibir y definir los servicios ecosistémicos de los glaciares, que en la indicación sustitutiva presentada por el Ejecutivo se basa en el valor económico de los glaciares, lo que es apoyado por el gremio minero, incluso cuestionando el que todos los glaciares cumplan dichos servicios. Mientras que desde la perspectiva ambientalista y de algunos diputados se planteó el considerar el concepto de funciones ecosistémicas de los glaciares, lo que implicaría incorporar aspectos ecológicos y no solo beneficio antrópico.

Uno de los aspectos importantes a considerar para comprender las diferentes dimensiones de este conflicto son las visiones contrapuestas de futuro y el significado del desarrollo. De acuerdo a Vallejos (2005), la profundización en Chile del modelo económico neoliberal, basado en la exportación de materias primas, ha provocado grandes externalidades ambientales y sociales, lo que determina el aumento de los conflictos socio ambientales.

En Garrido et al. (2015) se presenta un análisis acerca de las racionalidades existentes y de cómo son expresadas en los conflictos socioambientales, diferenciándose entre una racionalidad en la maximización de los beneficios económicos y que se caracteriza por una lógica antropocéntrica que concibe a la naturaleza como un medio para lograr objetivos, ya sean de "desarrollo" económico, lucro personal o sobrevivencia, y otra racionalidad alternativa o emergente y menos visibilizada, desde una perspectiva ambiental que tensiona y crítica la forma de desarrollo y vida moderna.

Otro de los elementos gatillantes de esta racionalidad emergente es la confirmación de la existencia de límites físicos en la tierra y sus "recursos" naturales, lo que se ha producido al considerar los informes científicos sobre cambio climático y las evidencias empíricas de sequías prolongadas, aumento en las temperaturas y aumento de fenómenos climáticos extremos.

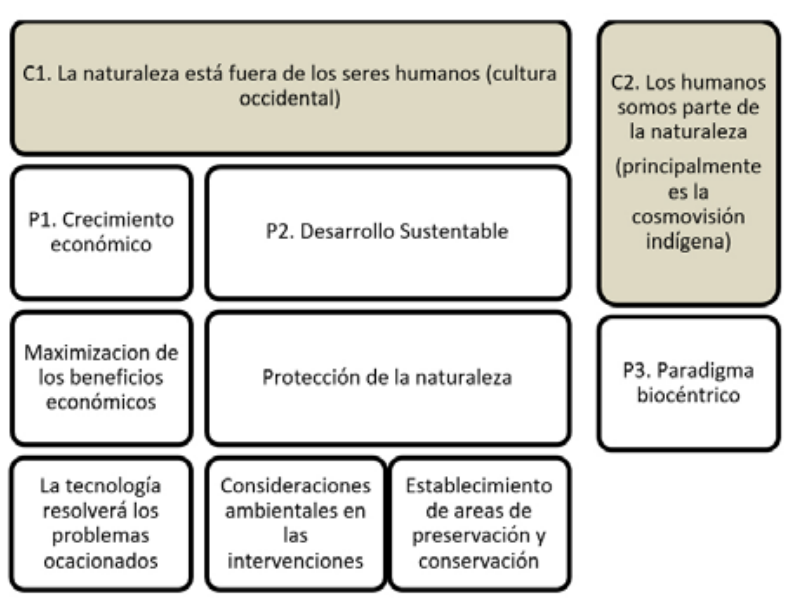

Figura 5. Cosmovisiones (C1 y C2) y paradigmas (P1, P2, P3) en torno a los conflictos socioambientales. Fuente: Elaboración propia.

De acuerdo a lo analizado, es posible diferenciar entre dos cosmovisiones diferentes desde las cuales se puede derivar en tres paradigmas desde los cuales se toma posición frente al conflicto. La siguiente ilustración (figura 5) es meramente referencial, ya que las cosmovisiones y paradigmas corresponden a una construcción que comprende reflexiones individuales y colectivas por lo que la existencia de matices hace que los bordes de estas cosmovisiones y paradigmas sea bastante difusa. 
En el caso analizado, la gran mayoría de las declaraciones analizadas no alcanzan a salir de la cosmovisión occidental, estableciéndose posturas que se sitúan exclusivamente dentro del paradigma de desarrollo sustentable, estableciéndose una gradiente en el nivel de sustentabilidad y la medida en que es necesaria la protección de la naturaleza, pero siempre encontramos dentro de los argumentos explícitos una visión utilitaria, ya sea dentro de los argumentos menos conservacionistas (se requiere evaluar caso a caso en virtud de impactos y la importancia del glaciar) hasta los más conservacionistas (se requiere proteger el $100 \%$ de los glaciares por ser estos reservas hídricas fundamentales), las únicas declaraciones de corte biocéntrico son aquellas referidas a la incorporación del concepto de funciones ecosistémicas por sobre servicios ecosistémicos.

\section{Discusión}

Si se considera la definición utilizada en este caso (Garrido et al., 2015) es posible describir el conflicto asociado a la iniciativa de Ley de Protección de Glaciares, como un proceso en el que se contraponen diferentes formas de abordar la protección, el desarrollo del país y el equilibrio entre ambos elementos, cuya temporalidad ya supera los dieciocho años y al parecer aún continuará, utilizándose en reiteradas oportunidades el espacio público a través de marchas y manifestaciones desarrolladas principalmente por uno de los grupos de actores en el conflicto (las ONG y sociedad civil) que exigen tanto al Poder Ejecutivo como al Legislativo, la concreción de la protección; mientras que los otros actores relevantes en el conflicto (Poder Ejecutivo, Poder Legislativo y empresas/gremios) utilizan espacios de negociación fuera del espacio público.

Respecto a la determinación del origen y los hitos más relevantes de este conflicto, se considera como punto de origen del conflicto el proyecto Pascua Lama, y como gatillante y acelerador del conflicto, la idea de la remoción y traslado de los glaciares afectados. La razón de atribuir a este proyecto en particular y a la declaración de la remoción de los glaciares el origen del conflicto se ampara en que las afectaciones a glaciares son bastante más antiguas en el país y fueron documentadas mucho antes que el conflicto "Pascua Lama" comenzara (Brenning y Azócar, 2010), pero no permearon como una preocupación ciudadana, restringiéndose únicamente al mundo científico y académico. Ante esto, se puede afirmar que el proyecto Pascua Lama hace pública y dota de relevancia una situación que ya ocurría con otros proyectos. En relación a esto, la declaración del titular del proyecto sobre la ejecución de acciones que son cuestionadas técnicamente repercute en la generación de desconfianza entre los actores interesados, pues aumenta la inseguridad ante cualquier propuesta posterior. Esto se condice con lo señalado por Vallejos, Boso y Zunino (2016) quienes señalan que la confianza/desconfianza es una de las dimensiones relevantes al analizar los riesgos asociados a conflictos socioambientales. En este punto es que podemos notar como el conflicto inicial por Pascua Lama toma una variante diferente que da pie al conflicto estudiado en el presente artículo, ya que la desconfianza no es solo contra el titular del proyecto, sino que comienza a extrapolarse permeando esferas técnicopolíticas e incluso técnico-científicas, ya que pone en duda la efectividad de la institucionalidad ambiental y la independencia existente entre los intereses económicos y políticos de las evaluaciones.

Metodológicamente, en esta investigación se utilizó un sistema más asociado a una tradición positivista, de recopilación de fuentes periodísticas provenientes de uno de los grupos periodísticos más influyentes del país (García, 2009), lo que permitió configurar la cronología, identificar los principales hitos y conformar grupos de actores involucrados en el conflicto. Sin embargo, esta información de medios oficiales parece insuficiente para presentar todo el espectro de opiniones y discursos, debido a los intereses editoriales en materia informativa. El diario El Mercurio asociado a un importante grupo económico del país de marcado acento ideológico neoliberal otorga gran relevancia a las noticias económicas (Navia, Osorio y Valenzuela, 2013), por lo que a través de la prensa oficial es difícil acceder a otros planteamientos y sería interesante la realización de un análisis que incorpore métodos de investigación cualitativa, que permitan ahondar en las profundidades discursivas, cuyo objetivo sería complementario al presente documento.

El análisis realizado no indica la presencia de cosmovisiones diferentes a la visión antropocéntrica, pero sí refleja una gradiente de posiciones respecto del paradigma de desarrollo que se quiere, moviéndose desde el paradigma del actual modelo de desarrollo extractivista a paradigmas de desarrollo sustentable a diferentes niveles. Probablemente, y sería interesante realizar el ejercicio, si se analizaran los argumentos contrarios a proyectos puntuales en casos donde exista presencia de población indígena, sea más amplia la mirada en cuanto a cosmovisiones, elementos que podrían analizarse en el conflicto por el proyecto Pascua Lama, en el que según Valenzuela, Penaglia y 
Basaure (2016), se construye un movimiento territorialétnico, que además de provocar una reivindicación de la condición étnica de sus habitantes, se genera un empoderamiento que propicia el desarrollo de un movimiento regionalista. En este contexto, Allison (2015) plantea que ciertas culturas habitantes de las faldas de cerros y nevados alrededor del mundo existen visiones animistas y chamánicas, donde las montañas y los glaciares representan a menudo las moradas de deidades, o incluso como la encarnación de la deidad misma, visión que ha permanecido infravalorada por la ciencia, la política y la economía. Por su parte, Bolados (2014) indica que, en el caso de conflictos aledaños al Salar de Atacama, se puede observar la incorporación de elementos medioambientalistas/conservacionistas como también demandas étnicas pendientes que relevaron estas luchas como estrategias de recuperación y control territorial entre las comunidades atacameñas del salar.

\section{Conclusiones}

De acuerdo a los antecedentes expuestos, se observa la evolución de un conflicto que nace de una iniciativa puntual y evoluciona convirtiéndose en un tema país que exige una ley de protección de glaciares nacional, que deriva en un conflicto de corte ético, releva posturas contrapuestas respecto al desarrollo del país y a la matriz económica, deja en evidencia las variadas formas de evolución, mutación y sinergia entre conflictos, lo que concuerda con el planteamiento de Fuenzalida y Quiroz (2012), quienes señalan que los conflictos ambientales en el último tiempo han trascendido lo local, lo cual busca representación y apoyo ciudadano a nivel nacional convirtiéndose en demandas socioambientales.

Respecto a los elementos, paradigmas y cosmovisiones en conflicto, en el análisis se visualizan tres posturas bastante claras, cuyos extremos parecen irreconciliables, y cuya postura intermedia, cuyo rol debiese ser el de hacer coexistir ambos extremos, parece ser que no cumple con las expectativas de un lado ni del otro, y en este punto subyace la existencia de la desconfianza en el rol del gobierno respecto a este rol de intermediario. Un elemento que resalta durante este proceso corresponde a la politización de los temas, entendida como la disputa sobre aquello que puede y debe ser socialmente decidido (PNUD, 2015); ya que es claro el uso de este conflicto en sus diversas variantes (puntual en el caso de proyectos específicos y nacional en el caso de los proyectos de ley) como elemento de diferenciación en campañas electorales.
Es claro que en el marco de la discusión de una ley que regule lo que es permitido y lo que no lo es sobre los glaciares y su entorno se deben conjugar y balancear debidamente distintos aspectos como, por ejemplo, proyectar adecuadamente un desarrollo económico sustentable, pero que no ponga en riesgo el patrimonio ambiental, ni a las comunidades y poblaciones que se benefician de los servicios ecosistémicos. No obstante, lo anterior, también una legislación debe ser lo suficientemente flexible como para poder detectar y actuar en casos de riesgo para la población.

Como último punto, es pertinente analizar cómo un conflicto que se origina en un proyecto puntual con elementos en conflicto de tipo altamente tangibles como el territorio y el agua y con actores claramente identificables por ser potenciales afectadores y afectados, puede evolucionar y derivar en poner en contraposición temas éticos y valóricos, y que cuestiona los paradigmas actuales de desarrollo, temas que van más allá de este conflicto en particular y que parecen estar replicándose en la mayoría de los conflictos socioambientales en el país, pues cuestionan el modelo de desarrollo extractivista, que genera grandes ganancias lejos de los territorios y que genera múltiples externalidades negativas para sus habitantes, situación que al parecer ya no solo disgusta a nivel local, sino que origina conflictos a nivel nacional.

\section{Referencias bibliográficas}

Allison, E. (2015). The spiritual significance of glaciers in an age of climate change. Wiley Interdisciplinary Reviews: Climate Change, 6(5), 493-508. https:/doi. org/10.1002/wcc.354 .

Astorga, E., Carrillo, F., Folchi, M., Grez, B., McPhee, B., Sepúlveda, C \& Stein, H. (2017). Evaluación de los Conflictos socioambientales de proyectos de gran tamaño con foco en agua y energía para el período 1998 al 2015. Santiago, Chile.

Bolados, P. (2014). Los conflictos etnoambientales de "Pampa Colorada" y "El Tatio" en el salar de Atacama, norte de Chile. Procesos étnicos en un contexto minero y turístico transnacional. Revista Estudios Atacameños. Arqueología y Antropología Surandinas, 48, 229- 248. https://dx.doi.org/10.4067/S0718-10432014000200015

Bórquez, R., Larraín, S., Polanco, R. \& Urquidi, J.C. (2006). Glaciares chilenos. Reservas Estratégicas de Agua Dulce para la sociedad, los ecosistemas y la economía. Santiago, Chile: LOM Ediciones. 
Brenning, A. \& Azócar, G. (2010). Minería y glaciares rocosos: impactos ambientales, antecedentes políticos y legales, y perspectivas futuras. Revista de Geografía Norte Grande, 47, 143-158. http://dx.doi.org/10.4067/ S0718-34022010000300008

Davies, B. \& Glasser, N. (2012). Accelerating recession in Patagonian glaciers from the "Little Ice Age" (c. AD 1870) to 2011. Journal of Glaciology,58(212), 1063-1084. http://dx.doi.org/10.3189/2012JoG12J026

El cuestionado proceso de remoción de glaciares. (28 de abril de 2005). El Diario de Atacama. Recuperado de http://www.diarioatacama.cl/prontus4_nots/site/ artic/20050427/pags/20050427223841.html

Fuenzalida, M. \& Quiroz, R. (2012). La dimensión espacial de los conflictos ambientales en Chile. Polis, Revista Latinoamericana, 11(31), 157-168. http://dx.doi. org/10.4067/S0718-65682012000100009

García, A. (2009). Realidad del Periodismo y los Medios en Chile. Revista ComHumanitas, 1(1), 71-77.

Garrido, M., Vallejos, A., \& Riquelme, A. (2015). Conflictos socioambientales en Chile: la re-emergencia de racionalidades alternativas. Cuadernos del CENDES, 32(88), 57-73.

Hernández, C. \& Sazo, D. (2015). Movilización y Resistencia Verde: Los Conflictos Socioambientales en Chile, 2000 - 2013. Revista de Gestión Pública, 4(2), 217-251.

Herr, L. (2014). Los Glaciares y su Protección Jurídica en Chile (Tesis Licenciatura en Ciencias Jurídicas y Sociales). Universidad de Chile, Santiago, Chile.

Instituto Geográfico Militar (IGM). (2014). Estudio y Propuesta de Terminología Asociada al Proyecto de Ley sobre Protección y Preservación de Glaciares. Santiago, Chile. Recuperado de https://www.camara.cl/pdf. prmTIPO=DOCUMENTOCOMISION\&prmID $=20878$

Instituto Nacional de Derechos Humanos (INDH). (2015). Situación de los Derechos Humanos en Chile. Informe Anual. Santiago, Chile.

Iribarren, P., Mackintosh, A. \& Norton K.P. (2015). Hazardous processes and events from glacier and permafrost areas: Lessons from the Chilean and Argentinean Andes. Earth Surface Processes and Landforms, 40(1), 2-21. https://doi.org/10.1002/esp.3524
Iribarren, P., Kinney, J., Shaefer, M., Harrison, S., Wilson, R., Segovia, A., Mazzorana, B., Farías, D., Reynolds, J. \& Glasser, N. (2018). Glacier protection laws: Potential conflicts in managing glacial hazards and adapting to climate change. Ambio, 47(8), 835-845. https://doi. org/10.1007/s13280-018-1043-X

Kronenberg, J. (2013). Linking Ecological Economics and Political Ecology to Study Mining, Glaciers and Global Warming. Environmental Policy and Governance, 23(2), 75-90. https://doi.org/10.1002/eet.1605

Loriaux, T. \& Casassa, G. (2013). Evolution of glacial lakes from the Northern Patagonian Icefield and terrestrial water storage in a sea-level rise context. Global and Planetary Change, 102, 33-40. https:// doi.org/10.1016/j.gloplacha.2012.12.012

Navia, P., Osorio, R. \& Valenzuela, F. (2013). Sesgo político en las lunas de miel presidenciales: El Mercurio y La Tercera, 1994-2010. En A. Arriagada, A \& P. Navia (ed). Intermedios. Medios de Comunicación y Democracia en Chile. Santiago de Chile: Ediciones Universidad Diego Portales.

Paul, F. \& Mölg, N. (2014). Hasty retreat of glaciers in northern Patagonia from 1985 to 2011. Journal of Glaciology, 60(224), 1033-1043. https://doi. org/10.3189/2014JoG14J104

Pollicardo, J. \& France, A. (2003). Manual de Capacitación para Mediadores Locales. Santiago: Fundación Casa de la Paz.

Programa de las Naciones Unidas para el Desarrollo (PNUD). (2015). Desarrollo Humano en Chile: Los tiempos de la politización. Santiago, Chile.

Reyes, F., Frontaura, C. \& Leturia, F. (2011). Capítulo II. Propuesta de mecanismos de resolución colaborativa de conflictos socioambientales. En Concurso Políticas Públicas: Propuestas para Chile (pp. 61-94). Santiago, Chile: Pontificia Universidad Católica de Chile.

Rivera, A. (1992). El glaciar Pio XI: Avances y retrocesos, el impacto sobre su entorno durante el presente siglo. Revista Geográfica de Chile Terra Australis, 36, 33-62.

Rivera, A., Aravena, J. \& Casassa, G. (1997). Recent fluctuations of glaciar Pio XI, Patagonia: Discussion of a glacial surge hypothesis. Mountain Research and Development, 17(4), 309-322. https://doi.org/10.2307/3674021 
Rivera, A. \& Casassa, G. (1999). Volume changes on Pio XI glacier, Patagonia: 1975-1995. Global and Planetary Change, 22(1-4), 233-244. https://doi.org/10.1016/ S0921-8181(99)00040-5

Rivera, A., Casassa, G., Acuña, C. \& Lange, H. (2000). Variaciones recientes de glaciares en Chile. Revista Investigaciones Geográficas, 34, 29-60. https:// doi:10.5354/0719-5370.2013.27709

Segovia, A. (2014). Caracterización glaciológica de Chile y valoración de servicios ecosistémicos de glaciares en base a mercados reales: estudio de caso del Monumento Natural El Morado (Tesis de Magister). Universidad de Chile, Santiago, Chile.

Segovia, A. (2015). Glaciares en el Sistema Nacional de Áreas Silvestres Protegidas por el Estado (SNASPE). Revista Investigaciones Geográficas, 49, 51-68. https:// doi.org/10.5354/0719-5370.2015.37513

Segovia, A. \& Videla Y. (2017). Caracterización Glaciológica de Chile. Revista Investigaciones Geográficas, 53, 3-24. https://doi.org/10.5354/0719-5370.2017.41739

Valenzuela, E., Penaglia, F. \& Basaure, L. (2016). Acciones colectivas territoriales en Chile, 2011-2013: de lo ambiental-reivindicativo al autonomismo regionalista. EURE, 42(125), 225-250. https://doi.org/10.4067/ s0250-71612016000100010

Vallejos, A. (2005). Los conflictos ambientales en una sociedad mundializada: Algunos antecedentes y consideraciones para Chile. Revista LIDER, 13, 193214. Recuperado de http://ceder.ulagos.cl/lider/index. php/11-segunda-epoca/10-lider-n-13.html

Vallejos, A., Boso, A. \& Zunino, H. (2016). La relevancia de la confianza en conflictos socioambientales por energía en Chile: los casos de "Castilla" e "Hidroaysén". Revista de Geografia Norte Grande, 63, 145-162. https://doi.org/10.4067/S0718-34022016000100009

Warren, C., Rivera, A. \& Austin, P. (1997). Greatest Holocene advance of Glaciar Pio XI, Chilean Patagonia: possible causes. Annals of Glaciology, 24, 11-15. https:// doi.org/10.3189/S026030550001185X 